\title{
Crown years for non-invasive cardiovascular imaging (Part IV): 30 years of cardiac computed tomography
}

\author{
E. E. van der Wall
}

Published online: 3 May 2013

(C) The Author(s) 2013. This article is published with open access at Springerlink.com

2013 is a remarkable year in cardiovascular medicine from a historical point of view. It can be considered a crown year for non-invasive clinical cardiovascular imaging as we can look back on 60 years of echocardiography, 40 years of nuclear cardiology, 30 years of cardiovascular magnetic resonance imaging, and 30 years of cardiac computed tomography. In previous Editor's Comments, 60 years of echocardiography, 40 years of nuclear cardiology, and 30 years of cardiovascular magnetic resonance have been described (Parts I, II, and II) [1-3]. In this Editor's Comment (Part IV) we will briefly look back to the roots of cardiac computed tomography and its main achievements over the past 30 years.

\section{Thirty years of cardiac computed tomography}

Although already in 1979 the Nobel Prize in Physics and Medicine was awarded to Sir Godfrey Newbold Hounsfield and Allan MacLeod Cormack for their discovery of computed tomography (CT), the research group directed by Charles Higgins (San Francisco, USA) were, in 1983, among the first to report that $\mathrm{CT}$ of the heart offers great promise for a definite application in cardiovascular clinical practice [4]. It was stated that ' $C T$ may eventually find its most important and clinically useful application in the diagnosis and management of heart disease' [4]. At that time electron-beam CT scanners provided useful clinical diagnostic information in patients with heart disease. Electron-beam CT already allowed anatomic evaluation of the heart in patients with arrhythmogenic right ventricular dysplasia, intra-cardiac shunts, congenital heart

\section{E. E. van der Wall $(\bowtie)$}

Interuniversity Cardiology Institute of the Netherlands (ICIN),

Netherlands Heart Institute (NHI), Catherijnesingel 52,

3501 DG Utrecht, the Netherlands

e-mail: e.e.van_der_wall@lumc.nl disease, hypertrophic cardiomyopathy, and coronary artery bypass grafts [5]. In 1984, the first cine-CT images were generated visualising myocardial wall thickening and motion [6]. After these initial cardiac CT investigations, the history and development of cardiac CT was directly associated with technological improvements occurring with each successive generation of CT scanners. Consequently, the true modern era of cardiac CT began in 1994 with the introduction of single-slice helical cardiac tomography [7]. With the advent of 4-slice CT in 1999 [8], multi-slice CT was introduced for cardiothoracic imaging to be followed by 16-slice tomography in 2002 [9]. Available since 2004, 64-slice CT systems were considered a prerequisite for successfully integrating cardiothoracic CT into routine clinical algorithms [10]. These developments were followed by the clinical introduction of dual source CT, 265-slice scanners, and 320-slice scanners between 2005 and 2010 [11-13]. By virtue of the strongly increased temporal and spatial resolution of these advanced scanning devices, the diagnostic accuracy of multi-slice CT angiography in coronary artery disease (CAD) has been significantly increased. Over the past 10 years multi-slice cardiac CT has become a standard non-invasive imaging modality in the USA, Japan and Europe (in particular Germany). In the Netherlands, research groups from Leiden (LUMC), Rotterdam (ErasmusMC), and Utrecht (UMCU) have significantly contributed to advances in clinical cardiac multi-slice CT.

In general, cardiac CT has two approaches: first, noncontrast enhanced CT to detect and quantify coronary calcium, and second, contrast-enhanced CT to detect non-obstructive and obstructive coronary atherosclerosis. Coronary calcium is considered a proven marker of the presence of atherosclerosis and the prognostic value of coronary calcium scoring is independent and incremental to the predictive value of traditional risk factors. In fact, an association between visible calcium on $\mathrm{CT}$ and the risk of cardiovascular events was 
already demonstrated in the early 1990s [14]. The presence of coronary calcium, as assessed by non-contrast enhanced $\mathrm{CT}$, does not necessarily imply the presence of a significant coronary obstruction [15]. There is a direct relation between the magnitude of the coronary calcium score and the presence of a coronary obstruction, which is located anywhere in the coronary tree and not necessarily at the calcific plaque site. The absence of coronary calcium is associated with a very low risk of adverse coronary events. Whether calcium scoring should be widely used in cardiovascular prevention strategies is still under debate [16]. There are many limitations of applying calcium scoring as a screening tool to broad populations as there is a lack of prospective randomised controlled trials showing that an abnormal calcium score impacts treatment decisions or clinical outcomes. Until these data are available, calcium scoring should be judiciously used by physicians in patients with different risk factors of developing cardiovascular events [17].

The presence of (non)obstructive coronary atherosclerosis is assessed by contrast-enhanced multi-slice CT coronary angiography [18]. In the clinical arena, multi-slice CT coronary angiography demonstrated a very high negative predictive value of more than $95 \%$, indicating that cardiac CT can be used as a reliable technique for excluding patients suspected of CAD $[19,20]$. Several meta-analyses of 64-slice CT studies reported sensitivities and specificities ranging from $86 \%$ to $99 \%$ and $88 \%$ to $97 \%$, respectively $[21,22]$. These studies indicate that multi-slice cardiac $\mathrm{CT}$, especially with 64 or more slice CT, has a high diagnostic accuracy for detection of CAD and could be used as an effective alternative to invasive coronary angiography in selected patients. Using both conventional coronary angiography and intravascular ultrasound (IVUS), the Leiden group were the first to confirm that the diagnostic performance of multi-slice CT angiography was superior in the evaluation of the presence or the absence of atherosclerosis when compared with the evaluation of significant stenosis [23]. Several studies have suggested that information about atherosclerosis derived from multi-slice CT coronary angiography may provide prognostic information [24, 25]. Interestingly, it was shown that the presence of a substantial non-calcified plaque burden was an independent predictor of events. As a result, CT coronary angiography has been proposed as a gatekeeper for invasive coronary angiography [26].

Currently, cardiac CT is mainly focussed on CT coronary angiography and current guidelines recommend $\mathrm{CT}$ angiography only for the exclusion of CAD [27]. The multi-slice CT scanning technique has improved significantly over the last decade, with acquisition of isotropic volume data in patients with high heart rate. Control of high heart rate with the use of beta-blocking agents is still commonly performed in many cardiac multi-slice CT examinations, including scans with the use of 320-slice CT or the dual source high-pitch spiral technique $[28,29]$. Further improvements in temporal resolution will contribute to the elimination of the aggressive procedure of heart rate control in patients with a heart rate of more than 70 beats $/ \mathrm{min}$. New developments aim to establish a role for $\mathrm{CT}$ in the functional imaging of the heart beyond the mere visualisation of anatomy [30]. Technological advances now offer the possibility to assess myocardial perfusion and viability by cardiac $\mathrm{CT}$ and initial clinical studies could already show a diagnostic accuracy comparable with the established imaging modalities $[31,32]$. Thus, cardiac CT may offer a combined approach of anatomical and functional imaging. Evaluation of the first-pass enhancement of the myocardium and CT-derived fractional flow reserve may have the potential to enhance the application of cardiac CT by providing the means to determine the haemodynamic relevance of coronary artery stenosis [33]. Another primary goal for cardiac CT is a 'snapshot image' of the entire heart in one single cardiac cycle, which can be obtained by using multi-slice CT systems with area detectors or dual-source CT systems with ECG-triggered high-pitch spiral [34]. Techniques to reduce the radiation dose to the patient, such as ECG-controlled dose modulation, ECG-triggered sequential $\mathrm{CT}$, low $\mathrm{kV}$ scanning, and iterative reconstruction, have gained considerable attention as a consequence of the ongoing discussion on radiation exposure by CT [35-37].

Hybrid imaging with PET-CT and SPECT-CT integrating both functional and anatomic information yields a better diagnostic performance than stand-alone CT, SPECT or PET [38-41]. Apart from the detection of CAD per se, cardiac CT has shown its value in other patient groups: patients with myocardial bridging, patients with coronary artery stents to assess restenosis, patients with congenital heart disease to evaluate right ventricular volumes and function, patients scheduled for radiofrequency ablation for atrial fibrillation to assess cardiac venous anatomy, and patients with valvular lesions to calculate dimensions of the aortic root or the mitral valve annulus [42-54].

To summarise, multi-slice cardiac CT has revolutionised non-invasive cardiac imaging both by calcium scoring and coronary $\mathrm{CT}$ angiography. Cardiac $\mathrm{CT}$ allows early detection of coronary atherosclerosis allowing adequate risk stratification and the timely instalment of preventive strategies. Currently, the main asset of cardiac $\mathrm{CT}$ is the exclusion of coronary atherosclerosis in patients suspected for CAD. Future directions of multi-slice CT angiography in the diagnosis of CAD lie in three main aspects: improvement of temporal resolution, reduction of radiation dose and judicious use of multi-slice CT. The definite role of multi-slice cardiac CT in the diagnosis and management of patients with stable angina can only be established after the performance of high-quality randomised studies with clinical outcomes as a primary outcome $[55,56]$. These studies should provide answers to the pivotal question 
of which patients benefit most from non-invasive coronary CT angiography and thus help to adequately select the right patients for this imaging procedure.

N.B. This Editor's comment highlights only a specific number of achievements in cardiac CT. For a more detailed description of the achievements by cardiac CT the reader is referred to more in-depth publications $[57,58]$.

\section{Of note; it has been put forward that thoracic CT scanning was developed in the early 1970s through revenues from selling the Beatles' records by Electric and Musical Industries (EMI). Several individuals have defined this as the Beatles' gift to medicine [59]. However, some controversies have arisen from analysis of this statement, making its correctness doubtful [60]. Whatever the truth, it keeps in public memory the name of the Beatles related to the development of CT scanning.}

Acknowledgments Careful reading and valuable suggestions by $\mathrm{Dr}$ Joanne Schuijf, $\mathrm{PhD}$, are gratefully acknowledged.

Funding None.

\section{Conflict of interest None declared.}

Open Access This article is distributed under the terms of the Creative Commons Attribution License which permits any use, distribution, and reproduction in any medium, provided the original author(s) and the source are credited.

\section{References}

1. van der Wall EE. Crown years for noninvasive cardiovascular imaging (part I): 60 years of echocardiography. Neth Heart J. 2013;21:161-2. doi:10.1007/s12471-013-0381-3.

2. van der Wall EE. Crown years for noninvasive cardiovascular imaging (part II): 40 years of nuclear cardiology. Neth Heart J. 2013. doi:10.1007/s12471-013-0392-0 [Epub ahead of print].

3. van der Wall EE. Crown years for non-invasive cardiovascular imaging (Part III); 30 years cardiovascular magnetic resonance. Neth Heart J. 2013. doi:10.1007/s12471-013-0406-y [Epub ahead of print].

4. Lipton MJ, Higgins CB. Computed tomography. The technique and its use for the evaluation of cardiocirculatory anatomy and function. Cardiol Clin. 1983;1:457-71.

5. Godwin JD, Califf RM, Korobkin M, et al. Clinical value of coronary bypass graft evaluation with CT. AJR Am J Roentgenol. 1983;140:649-55.

6. Lipton MJ, Higgins CB, Farmer D, et al. Cardiac imaging with a high-speed Cine-CT Scanner: preliminary results. Radiology. 1984;152:579-82.

7. Friese SA, Rieber A, Fleiter T, et al. Pulmonary nodules in spiral volumetric and single slice computed tomography. Eur J Radiol. 1994; 18:48-51.

8. Hu H. Multi-slice helical CT: scan and reconstruction. Med Phys. 1999;26:5-18.
9. Flohr T, Stierstorfer K, Bruder H, et al. New technical developments in multislice CT-Part 1: Approaching isotropic resolution with sub-millimeter 16-slice scanning. Rofo. 2002;174:839-45.

10. Nikolaou K, Flohr T, Knez A, et al. Advances in cardiac CT imaging: 64-slice scanner. Int J Cardiovasc Imaging. 2004;20:535-40.

11. Mori S, Endo M, Obata T, et al. Clinical potentials of the prototype 256-detector row CT-scanner. Acad Radiol. 2005;12:148-54.

12. Achenbach S, Anders K, Kalender WA. Dual-source cardiac computed tomography: image quality and dose considerations. Eur Radiol. 2008;18:1188-98. doi:10.1007/s00330-008-0883-3.

13. de Graaf FR, van Velzen JE, Witkowska AJ, et al. Diagnostic performance of 320-slice multidetector computed tomography coronary angiography in patients after coronary artery bypass grafting. Eur Radiol. 2011;21:2285-96. doi:10.1007/s00330-0112192-5.

14. Mautner SL, Mautner GC, Froehlich J, et al. Coronary artery disease: prediction with in vitro electron beam CT. Radiology. 1994;192:625-30.

15. Rumberger JA, Simons DB, Fitzpatrick LA, et al. Coronary artery calcium area by electron-beam computed tomography and coronary atherosclerotic plaque area. A histopathologic correlative study. Circulation. 1995;92:2157-62.

16. Vliegenthart R, Morris PB. Computed tomography coronary artery calcium scoring: review of evidence base and cost-effectiveness in cardiovascular risk prediction. J Thorac Imaging. 2012;27:296303. doi:10.1097/RTI.0b013e318254a00c.

17. Almoudi M, Sun Z. Coronary artery calcium score: re-evaluation of its predictive value for coronary artery disease. World J Cardiol. 2012;4:284-7. doi:10.4330/wjc.v4.i10.284.

18. Van Velzen JE, Schuijf JD, De Graaf FR, et al. Imaging of atherosclerosis: invasive and noninvasive techniques. Hellenic J Cardiol. 2009;50:245-63.

19. Schuijf JD, Pundziute G, Jukema JW, et al. Diagnostic accuracy of 64-slice multislice computed tomography in the noninvasive evaluation of significant coronary artery disease. Am J Cardiol. 2006;98:145-8.

20. Meijboom WB, Meijs MF, Schuijf JD, et al. Diagnostic accuracy of 64-slice computed tomography coronary angiography a prospective, multicenter, multivendor study. J Am Coll Cardiol. 2008;52:2135-44.

21. Abdulla J, Asferg C, Kofoed KF. Prognostic value of absence or presence of coronary artery disease determined by 64 -slice computed tomography coronary angiography a systematic review and meta-analysis. Int $\mathbf{J}$ Cardiovasc Imaging. 2011;27:413-20. doi:10.1007/s10554-010-9652-x.

22. Menke J, Unterberg-Buchwald C, Staab W, et al. Head-to-head comparison of prospectively triggered vs retrospectively gated coronary computed tomography angiography: Meta-analysis of diagnostic accuracy, image quality, and radiation dose. Am Heart J. 2013;165:154-63.e3. doi:10.1016/j.ahj.2012.10.026.

23. van Velzen JE, Schuijf JD, de Graaf FR, et al. Diagnostic performance of non-invasive multidetector computed tomography coronary angiography to detect coronary artery disease using different endpoints: detection of significant stenosis vs. detection of atherosclerosis. Eur Heart J. 2011;32:637-45. doi:10.1093/eurheartj/ ehq395.

24. Pundziute G, Schuijf JD, Jukema JW, et al. Prognostic value of multislice computed tomography coronary angiography in patients with known or suspected coronary artery disease. J Am Coll Cardiol. 2007;49:62-70.

25. van Werkhoven JM, Schuijf JD, Gaemperli O, et al. Incremental prognostic value of multi-slice computed tomography coronary angiography over coronary artery calcium scoring in patients with suspected coronary artery disease. Eur Heart J. 2009;30:2622-9. doi:10.1093/eurheartj/ehp272.

26. de Graaf FR, van Velzen JE, de Boer SM, et al. Non-invasive computed tomography coronary angiography as a gatekeeper for 
invasive coronary angiography. Int $\mathrm{J}$ Cardiovasc Imaging. 2013;29:221-8. doi:10.1007/s10554-012-0059-8.

27. Perrone-Filardi P, Achenbach S, Möhlenkamp S, et al. Cardiac computed tomography and myocardial perfusion scintigraphy for risk stratification in asymptomatic individuals without known cardiovascular disease: a position statement of the Working Group on Nuclear Cardiology and Cardiac CT of the European Society of Cardiology. Eur Heart J. 2011;32:1986-93. doi:10.1093/eurheartj/ehq235.

28. de Graaf FR, Schuijf JD, van Velzen JE, et al. Evaluation of contraindications and efficacy of oral Beta blockade before computed tomographic coronary angiography. Am J Cardiol. 2010;105:76772. doi:10.1016/j.amjcard.2009.10.058.

29. Neefjes LA, Dharampal AS, Rossi A, et al. Image quality and radiation exposure using different low-dose scan protocols in dualsource CT coronary angiography: randomized study. Radiology. 2011;261:779-86. doi:10.1148/radiol.11110606.

30. Flohr TG, Klotz E, Allmendinger $\mathrm{T}$, et al. Pushing the envelope: new computed tomography techniques for cardiothoracic imaging. J Thorac Imaging. 2010;25:100-11. doi:10.1097/ RTI.0b013e3181d7e898.

31. Underwood SR, Bax JJ, vom Dahl J, et al. Imaging techniques for the assessment of myocardial hibernation. Report of a Study Group of the European Society of Cardiology. Eur Heart J. 2004;25:815-36.

32. Becker A, Becker C. CT imaging of myocardial perfusion: possibilities and perspectives. J Nucl Cardiol. 2013;20:289-96. doi:10.1007/ s12350-013-9681-7.

33. Meijs MF, Cramer MJ, El Aidi H, et al. CT fractional flow reserve: the next level in non-invasive cardiac imaging. Neth Heart J. 2012;20:410-8. doi:10.1007/s12471-012-0306-6.

34. Achenbach S, Marwan M, Ropers D, et al. Coronary computed tomography angiography with a consistent dose below $1 \mathrm{mSv}$ using prospectively electrocardiogram-triggered high-pitch spiral acquisition. Eur Heart J. 2010;31:340-6.

35. Sun Z. Multislice CT, angiography in coronary artery disease: technical developments, radiation dose and diagnostic value. World J Cardiol. 2010;2:333-43. doi:10.4330/wjc.v2.i10.333.

36. van der Wall EE, Jukema JW, Schuijf JD, et al. $100 \mathrm{kV}$ versus 120 $\mathrm{kV}$ : effective reduction in radiation dose? Int J Cardiovasc Imaging. 2011;27:587-91. doi:10.1007/s10554-010-9693-1.

37. van der Wall EE, van Velzen JE, de Graaf FR, et al. 320-row CT scanning: reduction in tube current parallels reduction in radiation exposure? Int J Cardiovasc Imaging. 2012;28:193-7. doi:10.1007/ s10554-010-9762-5.

38. Scholte AJ, Schuijf JD, Kharagjitsingh AV, et al. Prevalence of coronary artery disease and plaque morphology assessed by multislice computed tomography coronary angiography and calcium scoring in asymptomatic patients with type 2 diabetes. Heart. 2008;94:290-5.

39. van Mieghem CA, de Feyter PJ. Combining non-invasive anatomical imaging with invasive functional information: an unconventional but appropriate hybrid approach. Neth Heart J. 2009;17:292-4.

40. Knaapen P, de Haan S, Hoekstra OS, et al. Cardiac PET-CT: advanced hybrid imaging for the detection of coronary artery disease. Neth Heart J. 2010;18:90-8.

41. Schaap J, de Groot JA, Nieman K, et al. Hybrid myocardial perfusion SPECT/CT coronary angiography and invasive coronary angiography in patients with stable angina pectoris lead to similar treatment decisions. Heart. 2013;99:188-94. doi:10.1136/heartjnl-2012-302761.

42. Wirianta J, Mouden M, Ottervanger JP, et al. Prevalence and predictors of bridging of coronary arteries in a large Indonesian population, as detected by 64-slice computed tomography scan. Neth Heart J. 2012;20:396-401. doi:10.1007/s12471-012-0296-4.

43. Bruschke AV, Veltman CE, de Graaf MA, et al. Myocardial bridging: what have we learned in the past and will new diagnostic modalities provide new insights? Neth Heart J. 2013;21:6-13. doi:10.1007/s12471-012-0355-x.
44. Winter MM, Romeih S, Bouma BJ, et al. Is cardiac CT a reproducible alternative for cardiac MR in adult patients with a systemic right ventricle? Neth Heart J. 2012;20:456-62. doi:10.1007/s12471-012-0310-x.

45. Cademartiri F, Schuijf JD, Pugliese F, et al. Usefulness of 64-slice multislice computed tomography coronary angiography to assess in-stent restenosis. J Am Coll Cardiol. 2007;49:2204-10.

46. Basalus MW, Said SA, Stassen CM, et al. Clinical and diagnostic features of partially anomalous pulmonary venous connection in an adult female patient: a case report and review of the literature. Neth Heart J. 2011;19:256-8. doi:10.1007/s12471-011-0101-9.

47. van Beek LM, Luijten H. Giant coronary aneurysms: threedimensional reconstruction. Neth Heart J. 2012;20:42-3. doi:10.1007/s12471-011-0150-0.

48. Van de Veire NR, Marsan NA, Schuijf JD, et al. Noninvasive imaging of cardiac venous anatomy with 64-slice multi-slice computed tomography and noninvasive assessment of left ventricular dyssynchrony by 3-dimensional tissue synchronization imaging in patients with heart failure scheduled for cardiac resynchronization therapy. Am J Cardiol. 2008;101:1023-9. doi:10.1016/j.amjcard.2007.11.052.

49. Jongbloed MR, Dirksen MS, Bax JJ, et al. Atrial fibrillation: multidetector row CT of pulmonary vein anatomy prior to radiofrequency catheter ablation-initial experience. Radiology. $2005 ; 234: 702-9$.

50. van der Wall EE. Ablation for atrial fibrillation: CT overlay or standard electroanatomical mapping? Neth Heart J. 2012;20:299 301. doi:10.1007/s12471-012-0301-y.

51. Tops LF, Van de Veire NR, Schuijf JD, et al. Noninvasive evaluation of coronary sinus anatomy and its relation to the mitral valve annulus: implications for percutaneous mitral annuloplasty. Circulation. 2007;115:1426-32.

52. Tops LF, Wood DA, Delgado V, et al. Noninvasive evaluation of the aortic root with multislice computed tomography implications for transcatheter aortic valve replacement. JACC Cardiovasc Imaging. 2008;1:321-30. doi:10.1016/j.jcmg.2007.12.006.

53. Achenbach S, Delgado V, Hausleiter J, et al. SCCT expert consensus document on computed tomography imaging before transcatheter aortic valve implantation (TAVI)/transcatheter aortic valve replacement (TAVR). J Cardiovasc Comput Tomogr. 2012;6:366-80. doi:10.1016/ j.jcct.2012.11.002

54. Braun J, van de Veire NR, Klautz RJ, et al. Restrictive mitral annuloplasty cures ischemic mitral regurgitation and heart failure. Ann Thorac Surg. 2008;85:430-6. doi:10.1016/j.athoracsur. 2007.08.040.

55. Weustink AC, de Feyter PJ. The role of multi-slice computed tomography in stable angina management: a current perspective. Neth Heart J. 2011;19:336-43. doi:10.1007/s12471-011-0096-2.

56. Schuetz GM, Schlattmann P, Achenbach S, et al. Individual patient data meta-analysis for the clinical assessment of coronary computed tomography angiography: protocol of the Collaborative MetaAnalysis of Cardiac CT (CoMe-CCT). Syst Rev. 2013;2:13. doi:10.1186/2046-4053-2-13.

57. Hurlock GS, Higashino H, Mochizuki T. History of cardiac computed tomography: single to 320-detector row multislice computed tomography. Int J Cardiovasc Imaging. 2009;25 Suppl 1:31-42. doi:10.1007/s10554-008-9408-z.

58. de Graaf FR, Schuijf JD, Delgado V, et al. Clinical application of CT coronary angiography: state of the art. Heart Lung Circ. 2010;19:107-16. doi:10.1016/j.hlc.2009.11.004.

59. Goodman LR. The Beatles, the Nobel Prize, and CT scanning of the chest. Radiol Clin North Am. 2010;48:1-7. doi:10.1016/ j.rcl.2009.09.008.

60. Maizlin ZV, Vos PM. Do we really need to thank the Beatles for the financing of the development of the computed tomography scanner? J Comput Assist Tomogr. 2012;36:161-4. doi:10.1097 RCT.0b013e318249416f. 